\title{
DEVELOPING UNDERGRADUATE NURSING MENTAL HEALTH AND ADDICTIONS TEACHING: PRACTICE AND EDUCATION PERSPECTIVES
}

\author{
Judith Honeyfield and Reghuram Ravindran
}

\section{INTRODUCTION}

Undergraduate nursing education must prepare students in a range of settings where people may present with mental health issues. The aim of this research was to consider if the current teaching and assessment approaches prepare Bachelor of Nursing (BN) graduates to meet stakeholder needs. Mental health nurses and teaching staff delivering mental health and addictions education were contacted to identify issues and good practice in the educational preparation for mental health nursing (MHN). Feedback from mental health nurses identified four key themes: (I) Normalising mental health is a health issue; (2) Active caring and compassion; (3) Learn the art of assessment - what do you see? (4) Back to basics - you are new to mental health, but not everything is new.

Mental health and addictions educators identified the emergence of two parallel models in mental health and addictions undergraduate education: (a) specialist content papers in mental health and addictions; (b) integration of mental health and addictions education across BN curricula. The response to this research was the development of a Year two mental health and addictions paper alongside integrated content in all papers of the BN curriculum to best position graduates to provide safe and effective MHN practice.

BN programmes in Aotearoa New Zealand offer a three-year degree preparing students to meet the Nursing Council of New Zealand competencies and successfully pass the national state examination to register as a nurse. All programmes are required to deliver core MHN concepts and knowledge, supported by a range of bio-psychosocial content and practice to support mental health and wellbeing (Ministry of Health [MOH], 20I8). All BN students complete mental health practicum experiences in a range of acute inpatient and community practice settings. The bicultural BN curriculum at Toi Ohomai Institute of Technology confirms Māori as tangata whenua (indigenous people of the land) and reflects the four articles of Te Tiriti o Waitangi as a founding document of our country. Core registered nurse competencies (Nursing Council of New Zealand, 2016) are developed and measured throughout the BN to ensure that all nursing practice is culturally safe (Honeyfield et al., 2020).

BN curricula are reviewed every five years by academic leaders and teaching teams for routine quality assurance, and feedback is sought from a range of practice settings, health agencies, stakeholders and students. Strategic policy reviews, professional body updates and current research is also analysed and considered in a review. In 2019, as part of a five-year review outcome at Toi Ohomai Institute of Technology, the mental health paper was found to require redevelopment and it was suggested that new pedagogical approaches be considered.

This strengthening of the mental health and addictions focus in the curriculum also responds to reduced recruitment of BN graduates into MHN practice (Lienert-Brown, 20I3; Stevens et al., 20I3). A number of initiatives have been instigated to reverse this trend (Cleary et al., 2006; Happell, 2008) and there have been reports of improved $\mathrm{MHN}$ and sector performance $(\mathrm{MOH}, 2019)$. Nevertheless, the literature continues to report negative undergraduate student experiences in practice and difficulties in recruitment (Hazelton et al., 20 I ; Hooper et al., 2016; Honeyfield et al., 2020; $\mathrm{MOH}, 2018$ ). 


\section{THE MENTAL HEALTH CONTEXT}

While most New Zealanders report good mental wellbeing most of the time, about one in five people will have had a diagnosable mental illness in the previous 12 months; and of these people, about one in 30 will experience severe mental illness and require specialist services $(\mathrm{MOH}, 2018)$. Over the last two years, the proportion of people seen in primary care practice with a diagnosed mental health issue has increased by 22 percent. In addition, an estimated 12 percent of New Zealanders will experience a substance use disorder in their lifetime, of whom 70 percent will have a co-existing mental health issue $(\mathrm{MOH}, 2018)$. Mental health and wellbeing are complex, and issues such as unemployment, poverty, discrimination, misuse of alcohol and drugs, abuse and family violence are further barriers to good mental health and wellbeing. These factors must be addressed, along with providing accessible, high-quality, effective support for people who are mentally unwell.

\section{THE MENTAL HEALTH AND ADDICTIONS WORKFORCE}

Nurses make up the largest group of regulated health professionals in mental health and addictions services, as shown in Figure I.

\section{Adult mental health and addictions workforce - vote health funded}

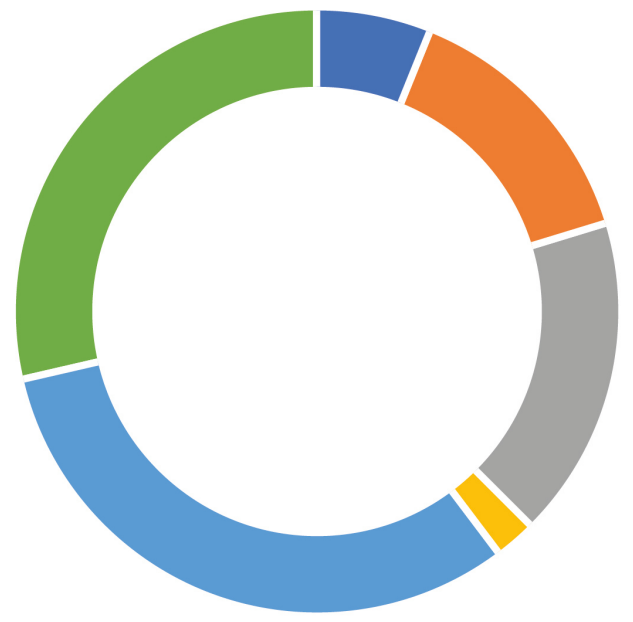

$6 \%$ Medical and other professionals

$2 \%$ Cultural workers

$14 \%$ Administration and management

$31 \%$ Support workers

$17 \%$ Allied health professionals

$28 \%$ Nurses

Figure I. Adult mental health and addictions workforce - public health funded. Source: $\mathrm{MOH}, 2018$. 
The Mental Health and Addiction Workforce Action Plan 2017-2021 (MOH, 2018) confirmed that all health and social service providers are responsible for promoting and maintaining mental wellbeing, signalling a need for collaboration and integrating a range of knowledge across the health continuum, which should be evolved in BN curricula. This responsibility includes developing values and attitudes required of nurses and health workers to create a culture where people's voice, along with their whānau (family), are core to discovering what really matters to the service consumers. The action plan $(\mathrm{MOH}, 20 \mathrm{I}, \mathrm{p} . \mathrm{I})$ identified four priority areas in mental health and addictions workforce requirements, creating a workforce that is:

I. Focused on people and improved outcomes

2. Integrated and connected across the continuum

3. Competent and capable

4. The right size and skill mix

The More Than Numbers (Te Pou o Te Whakaaro Nui, 2018) workforce survey, held in 2014 and 2018, reported that while the workforce had grown by 7 percent, and there had been an increase in services, only a minimal increase in funding occurred. Of note is increased staff turnover from 19 to 23 percent during the same time period, resulting in a greater need for addiction practitioners, support staff and social workers. In addition, improved representation of both Māori and Pacific peoples in the mental health and addictions workforce is needed due to the prevalence of mental health issues among Māori and Pacific communities $(\mathrm{MOH}, 2019)$.

These findings reinforce the need for improved addiction and therapeutic practice content in the $\mathrm{BN}$ and a focus on working in $\mathrm{MHN}$ as a career choice, as well as the need for a comprehensive mental health services review.

\section{MENTAL HEALTH AND ADDICTIONS INQUIRY}

A national mental health and addictions inquiry led to the publication of He Ara Oranga (New Zealand Government, 2018), and identified significant unmet needs for mental health and wellbeing services. He Ara Oranga presented 40 recommendations designed to set a clear direction for the mental health and addictions sectors and the community, with the government announcing that it had accepted in principle or in full 38 of the 40 recommendations $(\mathrm{MOH}, 2019)$.

However, He Ara Oranga has been criticised for the invisibility of nurses' perspectives (Cottingham, 2020) nurses make up 28 percent of the mental health and addictions workforce. O'Connor (2020) also takes issue with the He Ara Oranga recommendations and progress made toward achieving them and, while welcoming a shift toward better support for people with mild to moderate needs, suggests that a more pressing need is to improve services for people with complex and ongoing mental health requirements.

O'Connor (2020) believes that He Ara Oranga lacks attention to a range of areas that mental health nurses are concerned with. These include the need to support people who experience harm from substance use; improving mental health and addiction services for pregnant women and new mothers, including more integrated care for women and their babies, pointing out that suicide is the leading cause of maternal mortality, with Māori whānau most affected; expanding the capacity of forensic mental health services, noting a 25 percent increase in the prison population since 2013 , yet little increase in forensic mental health capacity; ensuring that all mental health and addictions services are culturally safe and work for Māori; reducing high rates of compulsion and the increasing use of seclusion, especially for Māori, and increasing specialty mental health and addictions services, which were under pressure. This lengthy list of service issues and requirements confirms that the mental health and addictions nursing workforce is an area facing multiple challenges, and provides important strategic workforce development pointers which and should be considered in content area in BN curricula. 
New initiatives signal important changes in MHN. In our region, Te Ara Tauwhirotanga has recently been established as new model for care (Lakes DHB, 202I), co-developed with tangata whaiora (people with lived experience of mental illness). This is a holistic model premised on tangata (people) experiences, their whānau, a caring, well-supported workforce and connectedness. Its underlying values (tikanga) are based in a te ao Māori world view: protecting and promoting wellbeing, access to help, and healing and recovery. The concept of taiao (environment) requires a local service presence and equitable outcomes. Taken together, this model of care informs tangata whaiora that their improved wellbeing is something they can expect in the future.

These recent publications, research efforts, professional positions and new models of care prompted this research project, with a view to furthering our understanding of the preparation of $\mathrm{BN}$ students from a mental health services perspective, and of the experiences of educators in developing $\mathrm{BN}$ curricula in national schools of nursing.

\section{BACKGROUND TO THE RESEARCH}

To prepare graduates for mental health and addictions nursing practice, and to equip them to respond effectively to people presenting to any care environment when changes to their mental health occur, we need broad evidence and stakeholder feedback in order to discover how our BN students' preparation is perceived. In addition, feedback from other nursing programmes, also responding to current and future $\mathrm{BN}$ education in mental health and addictions, will assist our redevelopment. We also recognise the importance of curricula links, including developing primary health care/health determinants, whānau/family-focused activities and collaborative multi-disciplinary teams working in a broad range of services including health, social, education and justice, that impact student understanding of mental health and wellbeing. Currently, many of these topics are covered superficially within the various mental health papers (or not at all), yet are integrated strands throughout the BN. This suggests that "a whole of BN" approach to mental health needs to be considered, and will be informed by this project.

The overarching research question that guided this study was: How are the mental health and addictions teaching, learning and assessment components of the $\mathrm{BN}$ programme positioning graduates to meet the needs of key stakeholders?

The aim of the research was to seek robust stakeholder and regional mental health sector feedback in order to inform curricula responses and to improve the mental health and addictions components of the $\mathrm{BN}$ programme.

Ethical approval for this research from Toi Ohomai Institute of Technology's research and human ethics committee was granted in 2019 (Ref. TRC 2019.034).

\section{METHODOLOGY}

A descriptive, exploratory, mixed-methods approach was undertaken, using an online survey and telephone interviews with mental health nurses/leaders from two district health boards (DHBs), two non-governmental organisations (NGOs) and two Māori mental health services. We also interviewed and surveyed mental health educators from six schools of nursing. Although the plan was to include all 16 schools, lack of timely contact, consent and follow-up meant that this number was reduced to six. The survey used both open and closed questions (quantitative and qualitative). Interviews were audio-recorded and transcribed. Participants were sent transcriptions to correct and verify accuracy. Data was analysed using key word and thematic analysis. The data was individually reviewed by two nurse educator researchers and one specialist mental health nurse to mitigate bias and/or misinterpretation. The researchers subsequently met to discuss, compare and agree findings, to ensure robust moderation and to select of pertinent quotations as evidence of our findings. 


\section{FINDINGS/DISCUSSIONS}

Mental health nurses were asked about preparation of current BN students including the extent of their knowledge base, gaps in preparation observable in new graduates and ways to collaborate to prepare BN graduates to meet workforce needs.

We found a high level of congruence between the six interview transcripts from service providers; most felt that current BN students' preparation was "better" or "improved over the last few years," with two participants agreeing that "we do get some very good students."

Four key themes or needs emerged in terms of BN students' preparation for $\mathrm{MHN}$ :

\section{Normalising mental health is a health issue}

As well as reporting concerns with recruitment, retention and the perception of MHN as "not very glamorous" and that it "was not prioritised in the BN," participants shared their perception that "students appear fearful of $\mathrm{MHN}$, yet demonstrate suitability on practicum." One participant shared their belief that "students as non-mental health nurses believe mental health patients need to be treated differently as we all know they don't." One participant was adamant that "mental health is a health issue and lots of mental health issues impact on physical health and physical health issues have a mental health component," advising that BN curricula need to "normalise mental health and take a holistic view."

\section{Active caring and compassion}

While one participant agreed that "we had some brilliant students" - describing their attributes as "keen, part of the team, how to be caring" - another participant suggested students were "unsure of what is a caring response," adding that "we shouldn't have to teach people that." Another participant asserted that "demonstrating compassion" and "active caring" are key models in the DHB.

\section{Learn the art of assessment - What do you see?}

In this theme, one participant reported that "they [students] have some idea of what they are observing, an important interaction between nurse and patient," suggesting that they "must have some understanding of what they are seeing." One participant asked, "who can be prepared for mental health?" acknowledging that "students have covered the first two years in BN so they understand practice." However, another participant shared a different perspective: "our assessment skills are different - around mental health Act," yet concluded, "I haven't found students that don't know about all this stuff."

Another participant reported that an important feature of their model is "listening to her [the patient] tell you how they will keep well," summarising: "it's a lot about uplifting the person - it works." Another participant asserted the "the biggest [need to know] is holistic care, the whare [house] is honesty, life values and beliefs - thus a different way of assessment."

\section{Back to the basics ... You are a new MHN practice, but not everything is new}

One participant believed that we need to "go back to the basics," described as being "non-judgemental, using empathy, basic listening, receiving a warm welcome ... acknowledging distress and how your communication and behaviour are received by other people."

All participants identified challenges with the current curriculum, with one stating that "it is too pressured." A second practitioner suggested that MHN is "crammed into a few weeks." 
The final question asked practitioners about ways to collaborate in order to prepare and attract more BN graduates to meet workforce needs. The feedback received suggested that shifting the timing and duration of $\mathrm{MHN}$ teaching to Year two in order to reduce pressure, change competence assessment forms (Nursing Council of New Zealand, 2016) and work more closely with preceptors would be a good move. One participant reminded us that "mental health is not for everyone ... we are all different people... but part of your job is to care."

Mental health and addictions educators were asked to outline their beliefs about the strengths of their current delivery of mental health and addictions content. Two parallel approaches emerged - the first, where specialist MHN papers were delivered and the second, where MHN content was integrated across papers in the curriculum.

\section{Model I: Specialist MHN core papers}

Participants gave feedback on the strength of the mental health and addictions component taught as speciality papers in Year two of the BN, alongside a Treaty of Waitangi course and rotating with six-week mental health practicums. The strength of this approach was identified by participants as follows:

- taught by highly experienced MHN teaching staff

- hands-on approaches to learning

- " "using a range of videos of people presenting, then students completing mental health assessments of video"

- group work and group activities

- $\quad$ strong online content with worksheets and quizzes, and using flipped classrooms

- "hearing voices" sessions (audio resources on Moodle for students to add to their mobile device, then listen to this material while they attempt to do a list of usual tasks including shopping)

- revisions in specialist mental health services including forensic

- involvement of consumers addressing students.

For participants, Dedicated Education Units (DEUs) have "proved very successful," with "good outcomes for students;" specifically, "working collaboratively with clinical staff and students gives the best outcome - better than one preceptor." In addition, DEUs foster "really good relationship[s] with DHBs - regular meetings with mental health services and organisation."

However, participants believe that improvements are required: "students need more communication - every psychiatric condition we present [to] them needs to spend time on how to communicate with someone." Another participant agreed that we "need more emphasis on communication rather than pathophysiology." A further issue was the clinical setting itself, where one participant believed that students are "not prepared for how burnt-out staff are;" they also identified staff shortages and noted that "it is hard to prepare them for a negative ward environment - negative irritable staff."

\section{Model 2: Integration (no standalone paper)}

In response to the first question about educational preparation for workforce needs and what could change, one participant asserted that "mental health and addictions is slotted in the BN curricula, in recognition that mental health is all inclusive of all other diagnosis." This participant identified the importance of their institution's bi-cultural approach, noting that "our emphasis on Mate Māori and Māori perspectives were [models] covered in Year two whaiora paper."

Another participant identified the outcome of a significant online component - "our mental health and addictions content is much reduced ... we are skimming" - drawing on a particular example: "inclusion of policies and legal consideration and overseas context is barely mentioned this year ... one hour each." Yet they emphasised the importance of mental health content: "the material aligns to Nursing Council competencies so students understand why they have to learn it." 
To another participant, "integration is required, which means all tutors have to be onboard with mental health aspects and in that respect, it is quite good;" they noted further that while "de-stigmatisation was the rationale, lecturers focused entirely on pathology [and] did not like it [integration]." The reason identified was that "They [educators] had to widen their brief as holistic is more sensible, people have co-morbidity, mental and physical issues." Another participant asserted that "[integration] is best practice across a lot of issues - for example, diabetes if it is really long-term, people might present with depression."

A second participant noted that their integrated programme is "inclusive of different ways of knowing and includes narrative and lived experience. The focus on recovery and human rights leads to the elimination of coercive practice, and supported patient decision making."

For participants, the strengths of integration included smaller classes, more one-to-one time and an allocated clinical practicum room onsite at the DHB for tutorials. In addition, the mental health team:

- $\quad$ have currency - teaching is based on current literature and resources

- $\quad$ teach BATOMI (Behaviour and appearance; Affect and mood; Thought and speech; Orientation, cognition and sensorium; Memory; Insight and judgement), a comprehensive mental health status assessment framework (Foster et al., 2021)

- $\quad$ use cultural assessment: "watch and go out with psychiatric triage team and cultural assessment team [who] do risk assessments"

- cover topics such as anxiety and depression in Year one

- connect shared knowledge and practice in an active learning environment using lived experience learning and simulations

- $\quad$ ensure pharmacology and pathophysiology is taught throughout.

For this model, challenges were identified as "condensing a whole semester in a few hours" and reporting "superficial" content. One participant, illustrating the need for ongoing development, noted that the integrated case study across the life span in chronic care did not include a mental health focus.

Asked about meeting workforce needs, participants responded, "we are fortunate to have good preceptors in placements to fill gaps in student knowledge," and are able to "incorporate more content workshops and refine as we go." Some topics required greater coverage; participants wanted "more on addictions, and trauma leading to addictions and mental health issues - only two hours of alcohol and other drugs," and wanted to "ask for increase in hours, especially for suicide."

One participant reported that their students did not really meet practice needs, a situation that "will change with increased collaboration across the faculty (of health/mental health strand community of practice group) and mental health sector." Further planning to meet workforce needs would include "more placements in inpatients or community services in Year two," confirming that DEUs are "used in inpatient, child and adolescent services, rehabilitation, mental health and medical wards and one NGO." This participant asserted that "preceptors do most of work."

One participant was positive about integration, summarising their views: "active blended learning, students use mental health knowledge and skill in all clinical areas and those who enter mental health workforce report they are well prepared for practice and ongoing learning." Another pointed out that "the [mental health] workforce can be institutionalised and do not always support supported decision making, to achieve less coercive practice."

Participants also identified the importance of the relationships formed during their time in practice and supervising students as important stakeholder engagement opportunities to assist curricula development. 


\section{DISCUSSION AND SUMMARY}

By sharing the voices of practitioners and educators, this research confirmed the strengths and challenges of current practice and the need to carefully consider ways to further develop mental health and addictions education in $\mathrm{BN}$ curricula. The two parallel models identified by participants each have their own strengths and challenges.

The Mental health and addiction workforce action plan (MOH, 2018), with its strong emphasis on integration and holistic models, sets a framework to ensure that tangata whaiora experience high levels of care, compassion and effective support in any health service they access. Mental health as a practice setting and nursing career speciality requires further normalisation and destigmatisation. Students must be exposed to practice environments where they can observe nursing role models sharing hope, care and compassion, and develop skills in assessment, observation and therapeutic responses in settings that support their learning. DEUs are highly valued as contributing to such a learning environment, developing education and practice collaborations, holistic care and culturally appropriate models and strategies. In this environment, BN students can consider the impact of the social determinants of health (World Health Organization, 2010) that contribute to mental health and wellbeing.

Lakes DHB's new model of care, Te Ara Tauwhirotanga, offers important values and approaches to develop collaborative integrated learning and teaching strategies reflecting kindness and compassion in the curricula. As a result, the academic leadership and teaching team responded to the findings of this research, designed to improve BN students' theory and practice experiences, in the following ways:

- developed a year-long specialist mental health and addictions paper for Year two of the BN

- increased curriculum hours for deeper exploration of preconceptions, destigmatisation and building confidence in strengths/person-centered approaches, kindness and care

- worked with Māori as tangata whenua, ensuring that Te Tiriti o Waitangi and cultural models and practices were embedded.

- developed further case scenario-based online learning and specialist learning packages for experiential learning

- facilitated whole-person assessment using holistic models

- further developed role play in order to expand communication and active caring approaches

- built on student clinical placement and lived experiences with new language and therapeutic approaches in learning activities

- created more support in clinical placements using experienced preceptors/nurses and expanded DEUs in mental health services

- used a competency assessment framework between education and practice to share experiences, clarify expectations and collaborate in supporting students and evaluation

- contributed to specific mental health content in all BN papers across the curriculum.

These curricula and learning and teaching redevelopments continue to be embedded and enhanced in 2021, including greater involvement with the mental health clinical teams, including shared professional development and specialist practice colleagues contributing to content.

\section{CONCLUSION}

By contributing essential perspectives from practice and MHN educators, this research has helped redevelop learning and teaching in mental health and addictions in the BN curriculum at Toi Ohomai Institute of Technology.

Relevant clinical placements and the ongoing development of DEUs and collaborative relationships with iwi Māori services, acute and community mental health service providers will all be essential to further develop the MHN workforce. Appropriate values and care/compassion models designed to advance wellbeing for tangata whaiora embedded across BN curricula will support the urgent need for ongoing service development summarised by O'Connor (2020). 
Further research that captures the perspectives of students in their preparation and intentions to join the MHN workforce is needed to monitor the impact of our redevelopment efforts and ongoing collaborative shaping of our practice.

Challenges continue for teaching mental health and addictions in nursing as Aotearoa New Zealand moves to a single tertiary education institutional model under Te Pükenga, a shift which will facilitate curricula examination and the evidence we use to develop our practice. Educational developments in nursing must reflect iwi Māori perspectives and unique stakeholder needs to prepare nurses for the future.

\section{ACKNOWLEDGEMENTS}

Thanks go to: Deborah Sims, Academic Leader, for her support for this research application and feedback on drafts of the proposal; Margie Proposch-Bacon, who drafted the initial proposal and conducted data collection prior to leaving the organisation; Toi Ohomai Institute of Technology, which funded time and travel for interviews, and the research office team who provided advice and commented on previous drafts leading up to ethical approval for this research.

Judith Honeyfield (PhD, ADN, RN) teaches on the Bachelor of Nursing (BN) and is Year three co-ordinator at Toi Ohomai. She supports BN students in theory and practice placements in primary, secondary and community settings. Her research interests include partnership-based relationships between education and practice, quality improvement and student preparation and experiences in mental health nursing.

(D) https://orcid.org/0000-0001-8045-6857

Reghuram Ravindran (MMHN, RN) facilitates and supports Year two BN students in mental health nursing at Toi Ohomai. Reg has a Masters in Nursing, specialising in mental health. He worked in acute inpatient mental health settings at Lakes DHB, following experience in aged residential care settings, prior to entering nursing education in 2020.

(D) https://orcid.org/0000-0001-7070-9240

\section{REFERENCES}

Cottingham, C. (2019). A mental health nurse reflects on he ara oranga. Kai Tiaki Nursing New Zealand, 45(2), 34-36.

Foster, K., Marks, P., O'Brien, A., \& Raeburn, T. (2021). Mental health in nursing: Theory and practice for clinical settings (5th ed.). Elsevier.

Happell, B. (2008). The importance of clinical experience for mental health nursing - Part I: Undergraduate nursing students' attitudes, preparedness and satisfaction. International Journal of Mental Health Nursing, 17.326-332 doi: 10.11।1/j.14470349.2008.00555.

Hazelton, M., Rossiter, R., Sinclair, E., and Morrall, P. (20II). Encounters with the 'dark side': New graduate nurses' experiences in a mental health service. Health Sociology review, 20(3), 172-186.

Health and Disability System Review - Hauora Manaaki ki Aotearoa Whānui. (2019). Health and disability system review - Interim report: Pürongo mō tēnei wā. https://systemreview.health.govt.nz/assets/HDSR-interim-report/5b33db77f5/H-and-D-fullinterim-report-August-2019.pdf

He Ara Oranga: Mental Health and addiction Inquiry (20I8). New Zealand Government. 
Honeyfield, J., Price, J., \& Ward, S. (2020). A practice-education partnership to improve mental health nursing development: Using feedback informed treatment approaches. In H. Hamerton \& C. Fraser (Eds.), Kotahitanga: He mahingā tahi working in partnership to improve outcomes for learners and communities. 2020 ITP Research Symposium, 50-57. http://itpresearch.ac.nz/2020-itp-research-symposium-proceedings/

Hooper, M., Browne, G., \& O'Brien, A. (2016). Graduate nurses' experiences of mental health services in their first year of practice: An integrative review. International Journal of Mental Health Nursing, 25(4), 286-298. https://doi.org//0.1/1//inm. I 192

Lakes District Health Board. (202I). Te ara tauwhirotanga. http://www.lakesdhb.govt.nz/Article.aspx?ID=10912

Lienert-Brown, M. F. (2013). Exploring undergraduate nursing students' experiences of their first clinical placement in an acute adult mental health inpatient service [Master's thesis, University of Otago]. OUR Archive. http://hdl.handle.net//0523/4424

Ministry of Health. (2018). Mental health and addiction workforce action plan 2017-2021 (2nd ed.). https://www.health.govt.nz/ publication/mental-health-and-addiction-workforce-action-plan-2017-2021

Ministry of Health (2019). Office of the Director of Mental Health and Addiction Services: Annual report 2017. Ministry of Health.

Nursing Council of New Zealand. (2016). Competencies for registered nurses. Author.

O'Connor, T. (2020). Mental health issues 'stubbornly similar': The mental health commissioner's biennial report on mental health and addiction services highlights some progress but says there's still plenty of work to do. Kai Tiaki Nursing New Zealand, 26(8), 25

Stevens, J., Browne, G., \& Graham, I. (2013). Career in mental health still an unlikely career choice for nursing graduates: A replicated longitudinal study. Int Journal of Mental Health Nursing,22(3) 213-220 https://doi.org/I 0.1 I I/j. I447-0349.20 I2.00860.x

Te Pou o te Whakaaro Nui. (2018). NGO adult mental health and addiction workforce: 2018 survey of secondary care health services [Report]. https://www.tepou.co.nz/uploads/files/resources/NGO-workforce-report-20I8.pdf

World Health Organization. (20l0). A conceptual framework for action on the Social Determinants of Health. WHO https://www. who.int/publications/i/item/9789241500852 